CASE 5.-On May 19th, 1881, I performed the operation on a male with malignant rectal disease. 'The local distress had caused him to seek relief. Fifteen days after the operation the patient returned to his home, ten miles off, and when heard of last summer he was following his occupation of engine tenting, and although feeling acutely the disagreeables incident to an artificial anus, still free in a great degree from the distressing and almost constant bowel pains.

CASE 6.-On June 9th, 1882, in a case of pelvic tumour, which had developed malignancy, and almost entirely occluded the bowel, I formed an artificial opening. The patient had become so exhausted from the local distress, coupled with the ravages the disease had inflicted on her general nutrition, that when the operation was agreed to death seemed imminent. The shock of the operation almost killed the patient, and although she lived for sixteen days perfectly freed from pain, still the wound never put on healing action.

CASE 7.-Four days after the above case, I again did the operation on a woman between sixty and seventy years of age for malignant rectal obstruction. Her recovery was uninterrupted and rapid, and relief from suffering most marked. The other day she called on me, grateful for what had been done for her.

Remarks.-Up till date these seven cases complete my experience of colotomy. In all the left lumbar operation was performed and the incision was oblique, runing from the margin of the last rib across the quadratus lumborum to and in front of the anterior superior iliac spine. No particular difficulty was experienced in any of my cases, and the loss of blood was but trifling. In one instance a fold of sub. peritoneal fat so simulated the flaccid bowel that I had actually transfixed it before finding ont my mistake. There is a danger of making the incision too far forward. This I did in Case 6, and in consequence wounded the reflected peritoneum, but no harm was done the patient therehy. Carbolised catgut was used in my first two cases to fix the edges of the opening to the skin, but because of its solution before firm union had taken place it was abandoned for Chinese silk. Colotomy is not practised so often as it ought to be, By diverting the fæces and so giving rest to diseased parts it may be directly curative in its action, as illustrated by Case 4, For such cases its more general adoption would prove a great gain in the treatment of cases which otherwise are intractable to treatment. The repugnance which patients frequently manifest even at the thought of such an operation would in great measure be removed when the temporary character of the artificial opening was explained, and the strong reasons for its production. When cure is altogether out of the question, owing to the malignant nature of the disease, we can replace intense, even in many cases incessant, pain by comparative comfort, and, unless the operation is delayed too long, prolong life. This is abundantly shown in the cases above recorded, and by an operation the mortality from which is very small. If patients suffering from malig. nant disease were seen sufficiently early, a combination of colotomy, as a temporary measure until healing of the parts had taken place, and excision of the diseased portion of bowel would offer the best chance of ultimate recovery. But unfortunately such patients as a rule come too late.

Nottingham.

\section{A RAPID METHOD OF DEMONSTRATING THE TUBERCLE BACILLUS WITHOUT THE USE OF NITRIC ACID.}

BY HENEAGE GIBBES, M.D., CURATOR OF THE ANATOMICAL MUSEUM, KING'S COLLEGE.

THE following method, which I have used for some time with great success, will I think prove useful to those requiring the demonstration of the tubercle bacillus for diagnostic purposes in a rapid manner. The great advantage consists in doing away with the use of nitric acid. The stain is made as follows: Take of rosanilin hydrochloride two grammes, methyl blue one gramme; rub them up in a glass mortar. Then dissolve anilin oil 3 c.c. in rectified spirit $15 \mathrm{c} \mathrm{c}$; add the spirit slowly to the stains until all is dissolved, then slowly add distilled water 15 c. c.; keep in a stoppered bottle.
To use the stain: The sputum having been dried on the cover-glass in the insual manner, a few drops of the stain are poured into a test tube and warmed; as soon as steam rises pour into a watch-glass, and place the cover-glass on the stain. Allow it to remain for four or five minutes, then wash in methylated spirit until no more colour comes away ; drain thoroughly and dry, either in the air or over a spiritlamp. Mount in Canada balsam. The whole process, after the sputum is dried, need not take more than six or seven minutes. This process is also valuable for sections of tissue containing bacilli, as they can be doubly stained without the least trouble. I have not tried to do this against time, but have merely placed the sections in the stain and allowed them to remain for some hours, and then transferred them to methylated spirit, where they have been left as long as the colour came out. In this way beautiful specimens have been made, without the shrinking which always occurs in the nitric acid proceas. The stains may be procured from Messrs. R. and J. Beck, 68, Cornhill, E.C., either in crystals or in solution, ready for use.

\section{AN INTERESTING MIDWIFERY CASE.}

\section{BY FRED. C. CORY, M.D.}

A sHonT record of the following complex case of midwifery may be interesting to the readers of THE LANCET.

A poor woman (multipara), the wife of a mechanic, was being attended by an uncertificated midwife for two days prior to my seeing the case. I could not get from this woman any clear statement of how such a condition of things had taken place. She was confused in her mind, having a constant craving for stimulating her nerve centres, which rendered her incapable of answering any questions, or even taking care of herself, much more of the patient. Of course this votary of Bacchus was very quickly dismissed from her post. The accompanying woodcut presents a rough

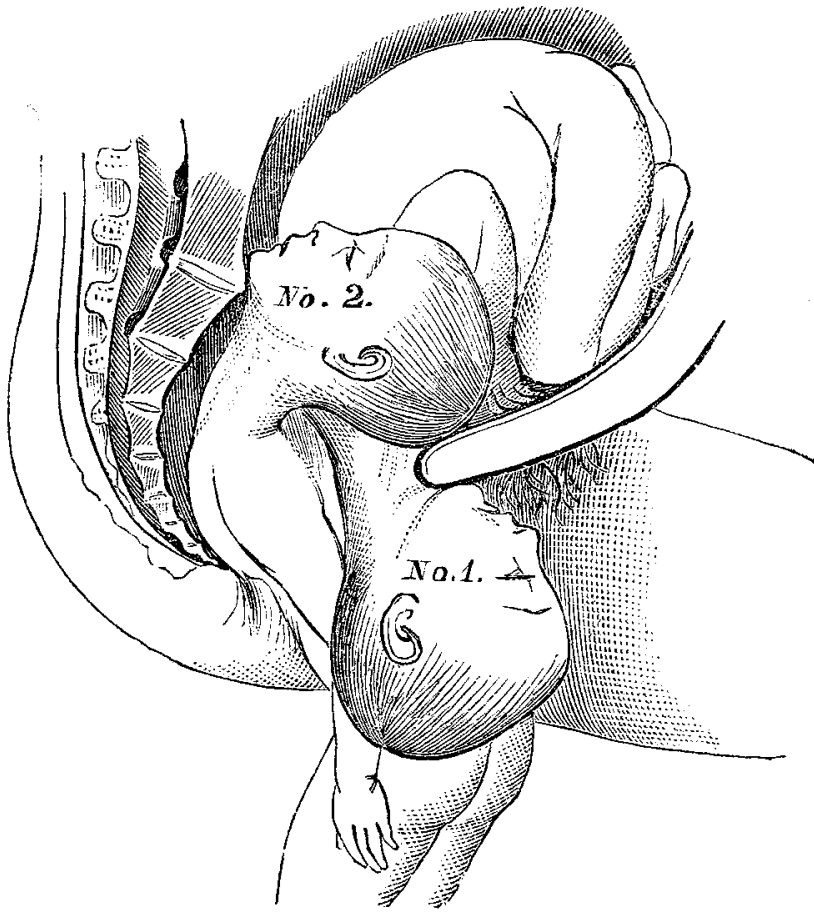

sketch of the position of each child in and out of the uterus, as far as I could ascertain by their external appearances. These children were in a high state of hæmic congestion, amounting almost to blackness. The child whose head was expelled, and whom I shall for the sake of distinction call No. 1, had the face towards the maternal pubes, the chin resting thereon, with its neck pressed closely under the arch by the back and shoulders of No. 2 ; the body was above the brim. No. 2 had the body from the arms and shoulders downwards expelled; the chin of this child rested on the brim of the maternal pelvis by the right sacro-iliac synchondrosis, the occiput impinging on the upper edge of the pubis to the right of the symphysis. The greatest difficulty was experienced in getting the index-finger upwards, so that 